\title{
Dual-DC/DC Strategy for Enhanced Efficiency in Solar Powered Energy Harvesting
}

\author{
C. Viehweger, T. Pfeifer, T. Keutel, O. Kanoun \\ Technische Universität Chemnitz, Reichenhainer Str. 70, 09126 Chemnitz, \\ christian.viehweger@etit.tu-chemnitz.de
}

\begin{abstract}
:
Powering autonomous sensor systems with ambient energy sources, called energy harvesting, has become an interesting field of research the last years. Solar based solutions belong to the most developed so far. In electronic systems the voltage of the solar cell must be regulated to match the supplied device, typically $3.3 \mathrm{~V}$ or $5 \mathrm{~V}$. It is also necessary to buffer energy to handle peaks in the current demand. These tasks can be fulfilled by different DC/DC converters, which normally have either a low startup voltage or a high efficiency. The work presented here describes the use of two complementary converters which make use of both characteristics to reach a low power operation also in difficult situations.
\end{abstract}

Key words: DC/DC Converter, Energy Harvesting, Solar Cell, Low Power, Efficiency

\section{Introduction}

Solar cells are a common source for energy harvesting solutions. The technology for both the cells and the electronics in this field are well-developed, although the work on efficiencies is still going on. One important point for the effectiveness of energy conversion is the adaption between solar cell and electrical circuit. According to the behavior of the cell as a nonlinear current source the output needs to be regulated for an optimal performance.[1] The varying voltage of the solar cell must be shifted to a usable and stable value also. Currently there are mainly two opposite options to realize this adaption. One is to reach very low start-up voltages, which causes that even small outputs of the solar cell can be used. The other one is a good efficiency for the transducer, which results in a higher start-up voltage as switching elements are required, which have fewer losses. Both versions act against each other as either the start-up voltage is low or the efficiency is high. The solution which should be preferred depends on the defined purpose for the transducer normally. In application fields like the low power indoor electronics area it is For wireless sensor networks located outdoors it is recommended to use a more efficient converter as the sun delivers a high level of energy every day. Overall there is no general solution currently.

This work aims on the development of an energy harvesting system which is able to make

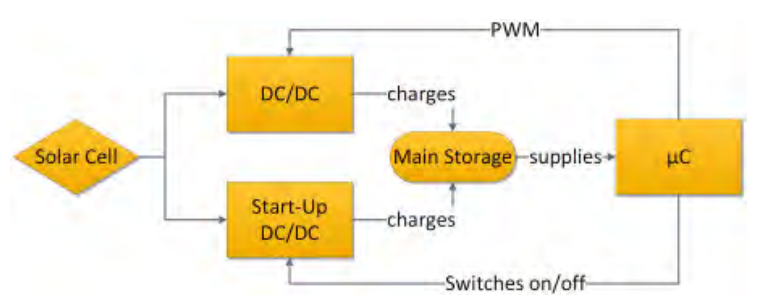

Figure 1: Schematic function diagram for the conversion with two different $D C / D C$ converters.

use of both, a low start-up voltage and a high efficiency converter. Therefore the two different $\mathrm{DC} / \mathrm{DC}$ strategies have been combined to work supportive here.

\section{DC/DC Circuits for Solar Cells}

State of the art solutions utilize either charge pumps or switching converters for voltage conversion and regulation. A variety of different wirings is possible for both principles. Overall a converter with a good input-output power ratio always needs to be regulated with a control signal. This control signal requires a microcontroller or active components to be generated. Such electronic parts again require a defined minimum voltage level. Most often this is above 1.8 Volt.[2] For energy harvesting solutions it is necessary to make use of illumination on solar cells that results in less Voltages also. This means to reach a minimum start-up voltage high efficient converters which require a control signal cannot be used. 


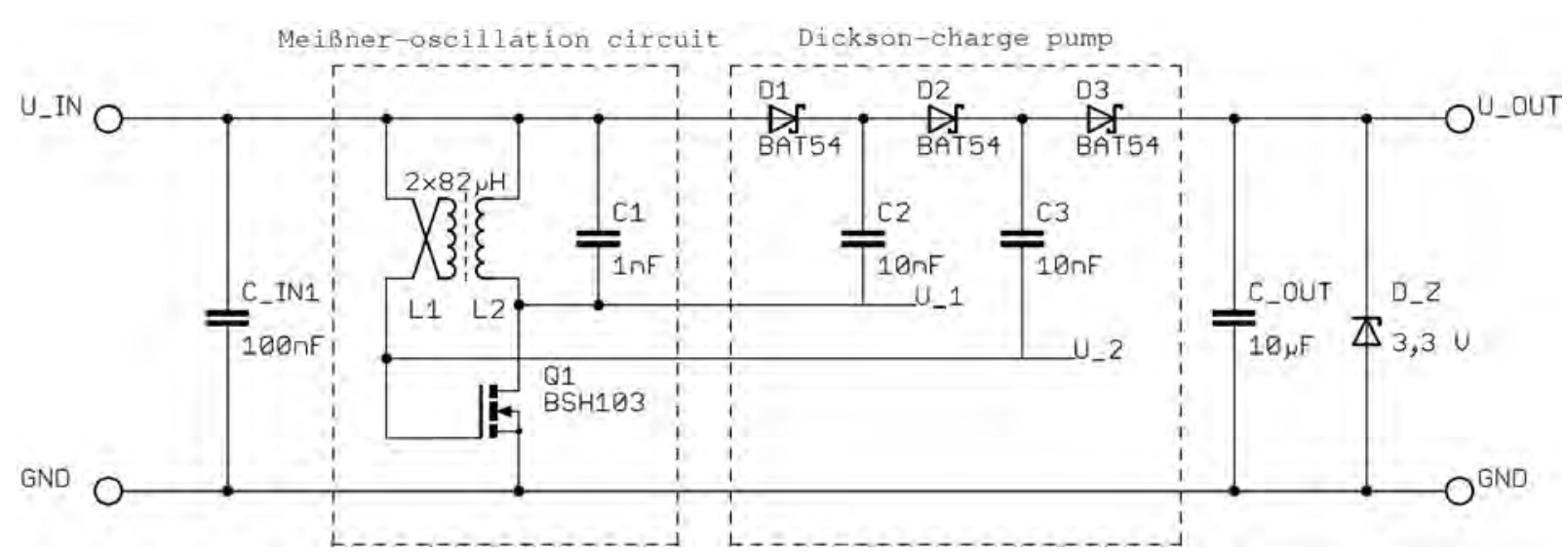

Figure 2: Low start-up voltage switching converter

For this reason the focus for this work on the one hand has been to have a circuit, which has a poor efficiency but a start-up voltage as low as possible. This DC/DC converter loads a capacitor which is used to power a microcontroller. Afterwards the microcontroller itself can produce a control signal which is used for a second DC/DC converter on the other hand, which has a distinct better efficiency. An overview for this setup can be seen in figure 1 .

For common boost converters at least an alternating DC voltage is required. Therefore an oscillation must be started by a microcontroller or another active circuit. This requirement and others like the low start-up voltage, the avoiding of integrated circuits as there is no supply for them at the beginning and the capability for the whole DC/DC system to start autonomous are to meet. For this reason a Meißner-oscillator [3] has been combined with a charge pump. The structure is shown in figure 2 .

In this circuit only one transistor is included, which defines the minimum start-up voltage. The Meißner oscillator is used to generate the control signal for the charge pump, which transfers the voltages of the capacitances to a higher level with every stage. The maximum output voltage is cropped with a Zener diode. The requirements on stability and accuracy are very low as this converter is only used to start a better one. The simulated efficiency of this circuit via SPICE is $49 \%$ for a conversion of 300 $\mathrm{mV}$ to $3.3 \mathrm{~V}$ with $1 \mathrm{~mA}$ input current.

For the second DC/DC the boost converter shown in figure 3 is used. The voltage of the input transistor is raised with an inductor and transferred to the output transistor. A diode avoids a current flow backwards to the input. As switching device a MOSFET is used which is controlled by the microcontroller. The efficiency of this circuit has been simulated to be around $75,2 \%$ including all transfer losses. The two most important design criteria are the coil and the MOSFET. The inductance should be selected as small as possible, because greater values mean more losses, but also large enough to deliver a sufficient current. The optimal value for the inductor can be calculated via [4]:

$$
L=\frac{V_{I N} \cdot\left(V_{\text {OUT }}-V_{I N}\right)}{\Delta I_{L} \cdot f_{S} \cdot V_{\text {OUT }}}
$$

with the approximated maximum ripple current through the coil

$$
\Delta L=(0.2 .0 .4) \cdot I_{O U T(\max )} \cdot \frac{V_{O U T}}{V_{I N}}
$$

Where,

$$
\begin{aligned}
& f_{S} \quad=\text { switching frequency } \\
& I_{\text {OUT(max) }}=\text { maximum output current }
\end{aligned}
$$

The second criteria which is important for the systems function is the MOSFET used for switching, as its charge transfer at the gate contributes notably to the overall losses. The transfer losses in the MOSFET can be calculated via:

$E_{V}=\frac{1}{2} \cdot V \cdot Q_{G}$

Where,

$$
Q_{G} \quad=\text { gate charge }
$$

The third important criteria for the design is the storage capacitor of the low voltage converter. It has to be large enough to guarantee a complete start-up of the microcontroller and the start-up of the more efficient converter. The at least necessary size which allows only just this operation can be calculated by: 
$C_{\min }=\frac{I_{\mu C+D C / D C} \cdot t_{\text {start }-u p}}{\Delta V}$

As both of the circuits have been built with discrete parts the efficiencies of $49 \%$ and 75.2 $\%$ can be enhanced with integrated devices in future.

\section{Implementation of the System}

The whole System consisting of both converters has been built on PCB after the simulation.

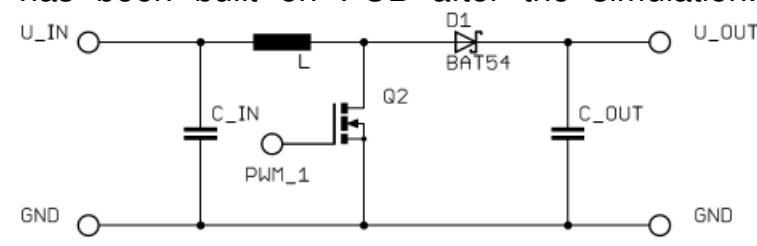

Figure 3: Boost converter with high efficiency [5]

Figure 4 shows a schematic illustration of the the different working intervals of the system. In phase 1 the self-oscillating low start-up voltage converter is active. As soon as a voltage at the storage capacitor of approximately 1.8 Volts has been reached, the microcontroller becomes active (phase II). It turns the first converter off and switches the high efficient converter on. The third phase shows the normal operation of the system after the initialization has been completed and an electronic system, e.g. a wireless sensor node, can be supplied.

Apparent from this construction two very important points can be concluded. One is that the rest of the system must draw as few current as possible. This concerns mainly the microcontroller, which must be controlled with a brownout circuit to prevent it from causing losses while the start-up converter is active. Otherwise the system is not able to power up as the power output from this converter is relatively low. The other important remark is that the alternation between both converters must be done very carefully. The first converter has to collect enough energy in the storage element for the controller and the second

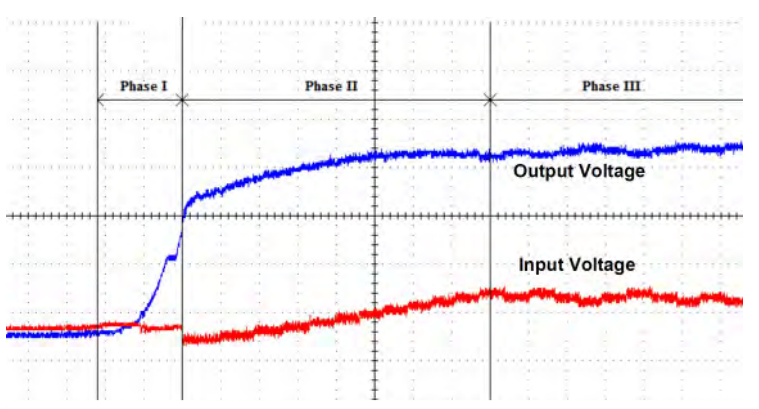

Figure 4: Schematic illustration of the different work phases of the converter converter to start. If the voltage collapses before the microcontroller has been completely initialized and entered his program code, the second converter will not start. Also the second voltage converter needs a few cycles to work as intended. This time span needs to be bridged with a small reserve by the buffered energy completely. Therefore an intelligent handling of the different state of functions is necessary to be able to change between the used converters. This includes that in a situation with none or less energy the load should be set in a low power state or even switched off completely until the supply becomes stable again. The use of the low start-up voltage converter should be avoided after the system has powered up.

\section{Conclusion and Outlook}

This work has shown that it is possible to have an energy harvesting solution for solar cells which has both a high efficiency and a low startup voltage. The effort on hardware does not significantly increase, as often a microcontroller in those systems is used anyway. Also the rest of the converter only consists of a MOSFET and a coil in addition to the common converter which has a low input voltage range. In this way the converter can adapt itself to different ambient conditions.

The focus in future work is to enhance the efficiency furthermore. This means the use of integrated devices and the improvement of the utilization of the solar cell, e.g. with an adapted maximum power point technology.

\section{References}

[1] T. Esram and P. L. Chapman, Comparison of photovoltaic Array Maximum Power Point Tracking Techniques, IEEE Transactions on Energy Conversion VOL. 22, 2007

[2] L. B. Hörmann, P. M. Glatz, C. Steger and R. Weiss, Energy Efficient Supply of WSN Nodes using Component-Aware Dynamic Voltage Scaling, 11th European Wireless Conference Sustainable Wireless Technologies (European Wireless), 2011

[3] G Kurz and W. Mathis, Oszillatoren: Schaltungstechnik, Analyse, Eigenschaften, ISBN: 3778522515, Hüthig Buch Verlag, Henidelberg, 1994

[4] B. Hauke, Basic Calculation of a Boost Converter's Power Stage, TI Application Report, SLVA372B, Nov. 2009

[5] F. Zach, Leistungselektronik: Ein Handbuch, ISBN: 3211892133, Springer Verlag, Wien, 2009 